\title{
Unusual presentation of primary sclerosing cholangitis
}

BC PineAu MD FRCPC, LP PATTEE MD FRCPC, S MCGUiRE MD CCFP, A SEKAR MD FRCPC, LJ SCULly MD FRCPC

BC Pineau, LP Pattee, S McGuire, A Sekar, LJ Scully. Unusual presentation of primary sclerosing cholangitis. Can J Gastroenterol 1997;11(1):45-48. A 23-year-old man presenting with acute pancreatitis and autoimmune hemolytic anemia was diagnosed with primary sclerosing cholangitis (PSC) without evidence of ulcerative colitis. This constellation of rare associations constitutes a unique mode of presentation of PSC. Within two years he also developed ankylosing spondylitis with sacroiliitis. Disordered immune regulation as a major factor in the mechanism of injury in PSC is supported by its increased association with other immunologically mediated disorders, most notably ulcerative colitis. Autoimmune hemolytic anemia, however, has been reported to be associated with PSC on only two occasions, and ankylosing spondylitis in the absence of ulcerative colitis is also unusual. In addition, the presentation of PSC with acute pancreatitis has rarely been described. This patient presented with several unusual features of PSC.

Key Words: Acute pancreatitis, Ankylosing spondylitis, Autoimmune hemolytic anemia, Sclerosing cholangitis

\section{Présentation inhabituelle de la cholangite sclérosante primitive}

RÉSUMÉ : Un jeune homme de 23 ans atteint de pancréatite aiguë et d'anémie hémolytique auto-immune a par la suite reçu un diagnostic de cholangite sclérosante primitive (CSP), sans signe de colite ulcéreuse. Cette constellation d'associations pathologiques rares constitue un mode unique de présentation de la CSP. En deux ans, le patient a également manifesté une spondylite ankylosante avec sacro-iliite. Le dérèglement immunitaire comme facteur principal du mécanisme pathologique de la CSP est appuyé par son association marquée avec d'autres troubles d'origine immunologique plus précisément avec la colite ulcéreuse. L'anémie hémolytique auto-immune a toutefois été signalée en association avec la CSP à deux occasions seulement. La spondylite ankylosante en l'absence de colite ulcéreuse est également inhabituelle. De plus, le tableau de CSP avec pancréatite aiguë a rarement été décrit. Ce patient présentait donc plusieurs caractéristiques inhabituelles de la CSP.
A ccumulating evidence suggests that primary sclerosing cholangitis (PSC) may be a disease of altered immunity. Although its pathogenesis is unknown, an autoimmune mechanism is supported by increased association of PSC with other immunologically mediated disorders, most notably ulcerative colitis. Autoimmune hemolytic anemia, however, is rarely associated with PSC, with only two reported cases previous to this report $(1,2)$.

The natural history of PSC is variable. In some it remains a subclinical condition for years, while others suffer from recurrent episodes of cholangitis, jaundice and pruritus early in the course of their illness (3). We report a case of PSC, unusual because of its presentation with acute pancreatitis and its association with other autoimmune conditions, ie, hemolytic anemia and ankylosing spondylitis but not ulcerative colitis. The latter associations may suggest that the immunological abnormality may be more generalized in some individuals.

\section{CASE PRESENTATION}

A 23-year-old heterosexual male of East Indian descent was admitted to hospital in December 1990 for evaluation of a three-month history of intermittent epigastric pain associated with fatigue, nausea, vomiting, jaundice and dark urine. There was no fever, chills or weight loss. There was no history of travel, blood transfusions, intravenous drug use, multiple sexual partners or exposure to toxic materials. He was on no medications and consumed alcohol infrequently.

Past medical and family history were negative for inflammatory bowel disease, abdominal surgery, liver disease and

Department of Medicine, University of Saskatchewan, Saskatoon, Saskatchewan; and Department of Family Medicine and Department of Medicine, University of Ottawa, Ottawa, Ontario

Correspondence and reprints: Dr LJ Scully, Ottawa Civic Hospital, 1053 Carling Avenue, Ottawa, Ontario K1Y 4E9. Telephone 613-761-4830, fax 613-761-5269

Received for publication June 20, 1995. Accepted May 21, 1996 

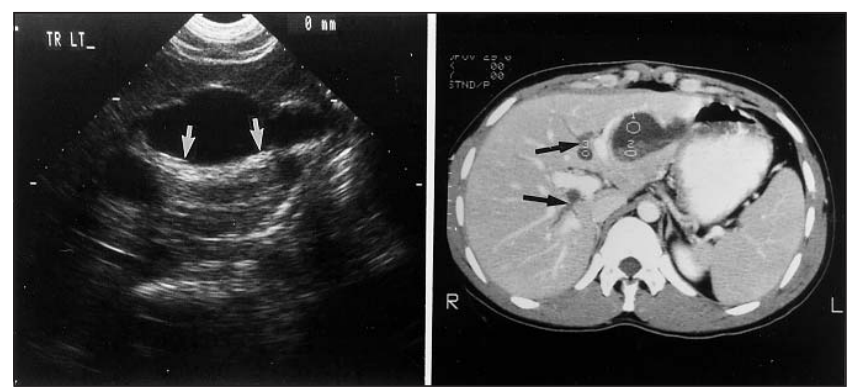

Figure 1) Left Transverse ultrasound of the left lobe of the liver showing bicameral cystic structure with echogenic debris in its dependent portion (arrows). Right Enhanced computerized tomography scan of the liver showing the same cystic structure with debris and intrahepatic ductal dilation (arrows)

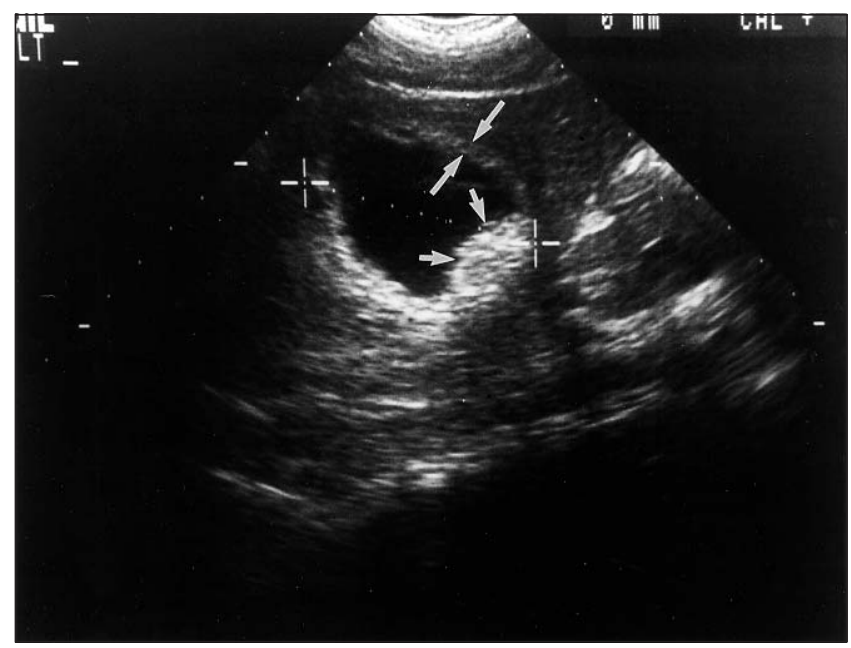

Figure 2) Sagittal ultrasound of the left lobe of the liver showing the thickened wall (long facing arrows) and echogenic debris (short arrows)

cholelithiasis. Apart from jaundice and epigastric tenderness, physical examination was normal and revealed no signs of chronic liver disease.

Normocytic, normochromic anemia was present; hemoglobin was $111 \mathrm{~g} / \mathrm{L}$. The peripheral smear showed polychromasia and spherocytes. Reticulocyte count was elevated at $11 \%$. Direct Coombs' test and testing for antiimmunoglobulin (Ig) $G$ antibodies were positive. Serum haptoglobin was $0 \mathrm{~g} / \mathrm{L}$. Leukocyte count was $9.5 \times 10^{9} / \mathrm{L}$ with normal differential and the platelet count was $452 \times 10^{9} / \mathrm{L}$. Total bilirubin was $145 \mathrm{~mol} / \mathrm{L}$ and conjugated bilirubin was $77 \mathrm{~mol} / \mathrm{L}$. Serum aspartate aminotransferase was $158 \mathrm{IU} / \mathrm{L}$, alanine aminotransferase $154 \mathrm{IU} / \mathrm{L}$ and alkaline phosphatase $882 \mathrm{IU} / \mathrm{L}$. Serum amylase was $1835 \mathrm{IU} / \mathrm{L}$ while the serum lipase was greater than $4000 \mathrm{IU} / \mathrm{L}$. Serum triglycerides, total cholesterol and calcium were normal. Serological tests for hepatitis A, B and C viruses were negative. Antismooth muscle and antimitochondrial antibodies were not detected. Testing for the human immunodeficiency virus (HIV) by ELISA was nonreactive. Human lymphocyte antigen (HLA) DR typing revealed that he was HLA DW52-, DR8-, DR14-, DRW52- and DQ1-positive.

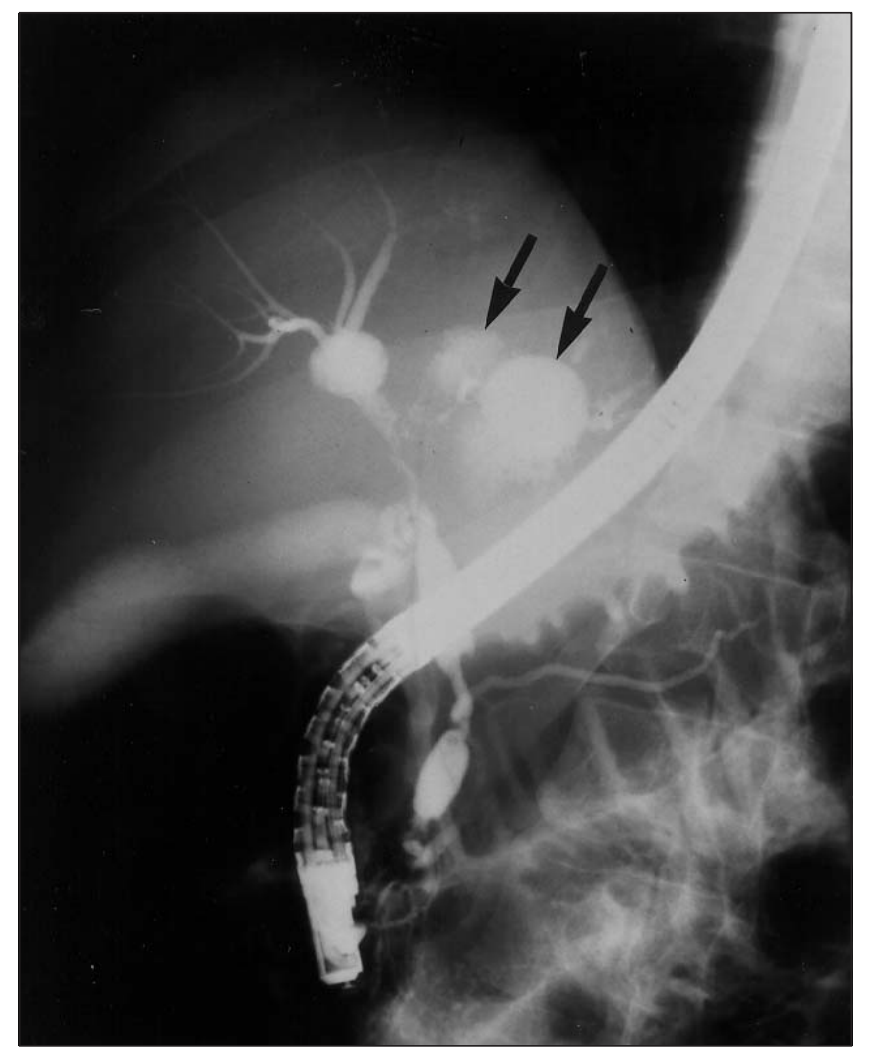

Figure 3) Cholangiogram showing widespread stricturing and saccular out-pouching of the biliary tree; filling of the cystic structures in the left hepatic lobe is also seen (arrows)

Abdominal sonography revealed a bicameral cystic structure consisting of a lobulated $49 \times 37 \mathrm{~mm}$ cavity communicating with an adjacent $15 \mathrm{~mm}$ similar lesion in the lateral segment of the left lobe of the liver (Figures 1,2) causing deviation of the left hepatic vein and portal triad. The walls were thickened, and echogenic debris was noted in the dependent portion of the largest lesion. There was no apparent connection to the biliary tree. Several similar smaller lesions were seen in the medial segment of the left lobe posteriorly. The pancreas was mildly and diffusely enlarged without evidence of peripancreatic fluid collection or ductal dilation. There was no cholelithiasis.

Computerized tomography (CT) of the abdomen suggested that the cystic lesions seen on ultrasound were focal biliary ductal ectasia with associated intraductal debris (Figure 1). There was mild dilation of the intrahepatic ductal system; the extrahepatic bile ducts, however, appeared normal. The pancreas was enlarged with no calcification.

Endoscopic retrograde cholangiopancreatography (ERCP) subsequently showed the biliary tree to have widespread stricturing and proximal dilation in both the intra- and extrahepatic ducts, including the cystic duct (Figure 3). There were two dominant strictures, one in the distal common bile duct showing the characteristic saccular out-pouchings typical of sclerosing cholangitis and the other located in the common hepatic duct. The cystic structures were in commu- 
nication with the biliary tree. The pancreatic duct was normal.

Prednisone $100 \mathrm{mg}$ daily and folic acid $5 \mathrm{mg}$ daily were begun to treat the hemolytic anemia. Three days following admission the amylase normalized and clinical status improved. He was discharged on a tapering course of prednisone but required readmission four weeks later for acute onset abdominal pain, obstructive jaundice and fever. Hemoglobin on admission was $137 \mathrm{~g} / \mathrm{L}$ while on prednisone $30 \mathrm{mg}$ daily. Leukocyte count was $14.4 \times 10^{9} / \mathrm{L}$ and the amylase was elevated to $622 \mathrm{IU} / \mathrm{L}$. Repeat abdominal sonography showed a slight decrease in the size of the cystic lesions. The patient recovered well following intravenous antibiotics.

Abdominal sonogram performed in September 1991, nine months after initial presentation, showed partial resolution of the cystic structures; the largest one was $34 \times 25 \mathrm{~mm}$, while some of the others completely disappeared.

Following two more episodes of acute pancreatitis a $12 \mathrm{~cm}, 7 \mathrm{~F}$ stent was positioned in the common bile duct in October 1991 and replaced with a larger stent four months later. There has not been any recurrence of acute pancreatitis since the first stent insertion. In August the stent was removed, and a cholangiogram revealed almost complete resolution of the extrahepatic strictures with intrahepatic duct disease remaining. In November 1992 he was started on ursodeoxycholic acid in an attempt to slow the progression of the liver disease. A flexible fibreoptic sigmoidoscopy at that time was normal.

The patient also developed significant low back pain and stiffness, and was found to have roentgenographic evidence of sacroiliitis. He is HLA-B27-positive, and a diagnosis of ankylosing spondylitis was made. He had an excellent response to nonsteroidal anti-inflammatory drug therapy.

At present the patient has no PSC symptoms. The autoimmune hemolytic anemia is quiescent off corticosteroids and the ankylosing spondylitis is well controlled.

\section{DISCUSSION}

PSC is an uncommon condition of unknown etiology characterized by chronic progressive inflammatory fibrosis of the intra- and extrahepatic biliary tracts, frequently leading to biliary cirrhosis, portal hypertension, liver failure and premature death (4-6). Most cases of PSC are detected by abnormal liver enzymes, jaundice and, less commonly, symptoms of cholangitis (3). This patient had an unusual clinical presentation with acute pancreatitis, possible hepatic abscesses and autoimmune hemolytic anemia.

Initial abdominal sonography revealed cystic structures that were not obviously connected to the biliary tree. However, while CT scan demonstrated these structures to be focal ectasia of the intrahepatic biliary tree, it failed to show the abnormal extrahepatic ductal system. These findings suggested a diagnosis of Caroli's disease among other less likely possibilities such as multiple hepatic abscesses or necrotic metastases. The importance of ERCP in the diagnosis of PSC is exemplified by this case; ERCP demonstrated widespread severe stricturing and proximal dilation of both the intra- and extrahepatic ducts, which facilitated exclusion of Caroli's disease and confirmation of PSC.

Although multifocal cholangiocarcinoma or cholangiocarcinoma complicating sclerosing cholangitis could not initially be excluded, the patient's young age, lack of progressive jaundice and prolonged survival make these unlikely. A sclerosing cholangitic process can be found in patients with AIDS (7); however, this patient has continued to have negative serology for HIV.

Subsequent CT scan and sonogram showed resolution of the cystic structures. Whether those structures were abscesses or (more likely) just focal duct dilations is unclear. In our patient the stricturing and beading of the intra- and extrahepatic bile ducts seen on ERCP did not change initially, but were altered only after prolonged stent and bile salt therapy. Therefore these bile duct lesions are unlikely to be secondary to other etiologies. A pattern typical of PSC, which normalizes following percutaneous drainage, has reportedly been induced by hepatic abscesses (8).

Acute pancreatitis, in the absence of cholendocholithiasis, was a presenting and recurrent complicating factor in our patient. CT scan and pancreatogram did not show any evidence of chronic pancreatitis, an association reported clinically $(9,10)$ and demonstrated endoscopically by changes on pancreatography (the changes resembling those seen in chronic pancreatitis) $(11,12)$. However, pancreatic ductal abnormalities were quite variable, occurring in $0 \%$ to $50 \%$ of patients with PSC in various series $(11,13)$.

We found only two cases of acute pancreatitis in the setting of PSC. Goldin et al (14) reported a case of severe recurrent acute pancreatitis as a presenting symptom of PSC, whereas Schep and Scully (15) reported acute pancreatitis complicating the course of PSC in a patient with sarcoidosis. Although the pathogenesis of acute pancreatitis in the setting of PSC remains to be elucidated, stricturing of the bile ducts or choledochopancreatic duct junction leading to biliary stasis likely plays a role. A recent prospective study showed biliary sludge to be an underestimated cause of acute idiopathic pancreatitis (16). Considering the physiological and anatomical changes in PSC, it is surprising that acute pancreatitis does not occur more frequently.

Despite its rare association with ulcerative colitis (17), autoimmune hemolytic anemia has been reported on only two occasions in PSC without evidence of ulcerative colitis $(1,2)$. Besides its well recognized association with inflammatory bowel disease $(18,19)$, PSC has less commonly been associated with a variety of other diseases that may also be immunologically mediated, including Riedel's struma, retroperitoneal fibrosis (20), Sjögren's syndrome (21), sarcoidosis (15), hyperthyroidism (2), orbital fibrosis, Peyronie's disease, histiocytosis $\mathrm{X}$, angioblastic lymphadenopathy (22) and immunodeficiency syndromes $(7,23)$.

Although the pathogenesis of PSC has yet to be defined, many immunological abnormalities have been observed such that disordered immune regulation has been postulated as a major factor in the mechanism of injury. HLA-B8 and HLA-DR3 antigens are common in PSC and associated with 
an increased incidence of other autoimmune diseases $(19,24)$. Other immunological abnormalities in PSC include elevated levels $(25,26)$ and reduced clearance $(27,28)$ of circulating immune complexes, increased complement metabolism $(26,29)$ and circulating autoantibodies against the colon and the portal tract $(30,31)$.

In addition, disturbances of cell-mediated immunity have also been reported in PSC with enhanced autoreactivity of $\mathrm{T}$ lymphocytes (32), inhibited leukocyte migration in response to biliary antigens (33), lymphocyte infiltration in areas of portal damage suggesting immune-mediated destructive processes, and altered lymphocyte subset ratios, yielding a significant decrease in both the absolute number and relative proportions of suppressor/cytotoxic cells (34).

This patient progressed to develop sacroiliitis with ankylosing spondylitis, a well known extraintestinal manifestation of ulcerative colitis, but rarely encountered in PSC. Interestingly, there is no evidence of ulcerative colitis in our patient, who has an entirely normal fibreoptic sigmoido-

\section{REFERENCES}

1. Scully RE, Mark EJ, McNeely WF, et al. Case records of the Massachusetts General Hospital. Case 3-1991. N Engl J Med 1991;324:180-8.

2. Moeller DD. Sclerosing cholangitis associated with autoimmune hemolytic anemia and hyperthyroidism. Am J Gastroenterol 1985;80:122-5

3. Helzberg JH, Petersen JM, Boyer JL. Improved survival with primary sclerosing cholangitis. A review of clinicopathologic features and comparison of symptomatic and asymptomatic patients. Gastroenterology 1987;92:1869-75.

4. LaRusso NF, Wiesner RH, Ludwig J, et al. Primary sclerosing cholangitis. N Engl J Med 1984;310:899-903.

5. Wiesner RH, LaRusso NF. Clinicopathologic features of the syndrome of primary sclerosing cholangitis. Gastroenterology 1980;79:200-6.

6. Chapman RWG, Marborgh BA, Rhodes JM, et al. Primary sclerosing cholangitis: a review of its clinical features, cholangiography, and hepatic histology. Gut 1980;21:870-7.

7. Margulis SJ, Honig CL, Soave R, et al. Biliary tract obstruction in the acquired immunodeficiency syndrome. Ann Intern Med 1986;105:207-10.

8. Steinhart AH, Simons M, Stone R, et al. Multiple hepatic abscesses: cholangiographic changes simulating sclerosing cholangitis and resolution after percutaneous drainage. Am J Gastroenterol 1990;85:306-8.

9. Waldram R, Tsantoulas D, Kopelman H, et al. Chronic pancreatitis, sclerosing cholangitis, and sicca complex in two siblings. Lancet $1975 ; \mathrm{i}: 550-2$.

10. Gurian LE, Keeffe EB. Pancreatic insufficiency with ulcerative colitis and pericholangitis. Gastroenterology 1982;82:581-5.

11. MacCarty RL, LaRusso NF, Wiesner RH, et al. Primary sclerosing cholangitis: findings on cholangiography and pancreatography. Radiology 1983;149:39-44.

12. Palmer KR, Cotton PB, Chapman M. Pancreatogram in cholestasis. Gut 1984;25:424-7.

13. Fausa O, Kolmannskog F, Ritland S. The pancreatic ducts in primary biliary cirrhosis and sclerosing cholangitis. Scand J Gastroenterol 1985;20(Suppl 107):32-5.

14. Goldin E, Libson E, Wengrower D, et al. Severe acute pancreatitis as the presenting symptom of primary sclerosing cholangitis: treatment by endoscopic insertion of a biliary stent. Int Surg 1990;75:58-60.

15. Schep GN, Scully LJ. Primary sclerosing cholangitis and sarcoidosis: an unusual combination. Case report and review of the literature. Can J Gastroenterol 1990;4:489-94.

16. Lee SP, Nicholls JF, Park HZ. Biliary sludge as a cause of acute pancreatitis. N Engl J Med 1992;326:589-93.

17. Altman AR, Maltz C, Janowitz HD. Autoimmune hemolytic anemia in ulcerative colitis. Report of three cases, review of the literature, and evaluation of modes of therapy. Dig Dis Sci 1979;24:282-5. scopy. The pathogenesis of ankylosing spondylitis is poorly understood but immune-mediated mechanisms have been implicated.

All these findings suggest an important role for immunoregulatory dysfunction in the pathogenesis of PSC and give support to the increasing association with immunologically mediated diseases such as autoimmune hemolytic anemia and ankylosing spondylitis.

In summary, we report a unique clinical presentation of PSC in which acute pancreatitis and autoimmune hemolytic anemia were simultaneously encountered and ankylosing spondylitis subsequently developed, in the absence of ulcerative colitis.

\section{ADDENDUM}

Since submission of this paper, another report of this association of diseases has been published (Can $J$ Gastroenterol 1996;10:301-303).

18. Thorpe MEC, Scheuer PJ, Sherlock S. Primary sclerosing cholangitis, the biliary tree, and ulcerative colitis. Gut 1967;8:435-48.

19. Schrumpf E, Fausa O, Forre O, et al. HLA antigens and immunoregulatory $\mathrm{T}$ cells in ulcerative colitis associated with hepatobiliary disease. Scand J Gastroenterol 1982;17:187-91.

20. Bartholomew LG, Cain JC, Woolner LB, et al. Sclerosing cholangitis: its possible association with Riedel's struma and fibrous retroperitonitis - report of two cases. N Engl J Med 1963;269:8-12.

21. Montefusco PP, Geiss AC, Bronzo RL, et al. Sclerosing cholangitis, chronic pancreatitis, and Sjogren's syndrome: a syndrome complex. Am J Surg 1984;147:822-6.

22. Wiesner RH, Ludwig J, LaRusso NF, et al. Diagnosis and treatment of primary sclerosing cholangitis. Semin Liver Dis 1985;5:241-53.

23. Roulot D, Valla D, Brun-Vezinet F, et al. Cholangitis in the acquired immunodeficiency syndrome: report of two cases and review of the literature. Gut 1987;28:1653-60.

24. Chapman RW, Kelly PMA, Heryet A, et al. Expression of HLA-DR antigens on bile duct epithelium in primary sclerosing cholangitis. Gut 1988;29:422-7.

25. Bodenheimer HC Jr, LaRusso NF, Thayer WR Jr, et al. Elevated circulating immune complexes in primary sclerosing cholangitis. Hepatology 1983;3:150-4.

26. Senaldi G, Donaldson PT, Magrin S. Activation of the complement system in primary sclerosing cholangitis. Gastroenterology 1989;97:1430-4

27. Minuk GY, Angus M, Brickman CM, et al. Abnormal clearance of immune complexes from the circulation of patients with primary sclerosing cholangitis. Gastroenterology 1985;88:166-70.

28. Minuk GY, Hershfield NB, Lee WY, et al. Reticuloendothelial system $\mathrm{Fc}$ receptor-mediated clearance of $\mathrm{IgG}$-tagged erythrocytes from the circulation of patients with idiopathic ulcerative colitis and chronic liver disease. Hepatology 1986;6:1-5.

29. Brinch L, Teisberg P, Schrumpf E, et al. The in vivo metabolism of C3 in hepatobiliary disease associated with ulcerative colitis. Scand J Gastroenterol 1982;17:523-7.

30. Chapman RW, Cottone M, Selby WS, et al. Serum autoantibodies, ulcerative colitis and primary sclerosing cholangitis. Gut 1986;27:86-91.

31. Mandal A, Dasgupta A, Jeffers L, et al. Autoantibodies in sclerosing cholangitis against a shared peptide in biliary and colon epithelium. Gastroenterology 1994;106:185-92.

32. Lindor KD, Wiesner RH, LaRusso NF, et al. Enhanced autoreactivity of T-lymphocytes in primary sclerosing cholangitis. Hepatology 1987;7:884-8

33. McFarlane IG, Wojcicka BM, Tsantoulas DC, et al. Leukocyte migration inhibition in response to biliary antigens in primary biliary cirrhosis, sclerosing cholangitis, and other chronic liver diseases. Gastroenterology 1979;76:1333-40.

34. Lindor KD, Wiesner RH, Katzmann JA, et al. Lymphocyte subsets in primary sclerosing cholangitis. Dig Dis Sci 1987;32:720-5. 


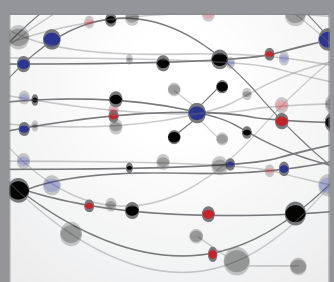

The Scientific World Journal
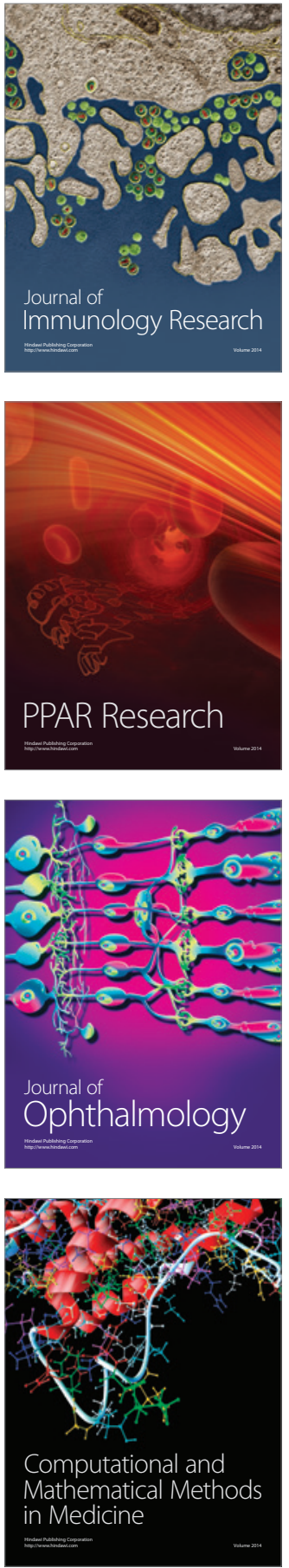

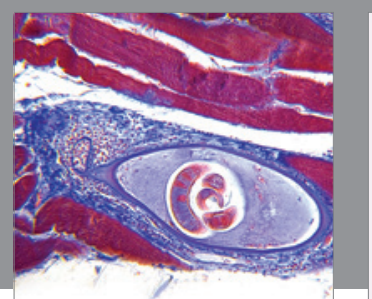

Gastroenterology Research and Practice

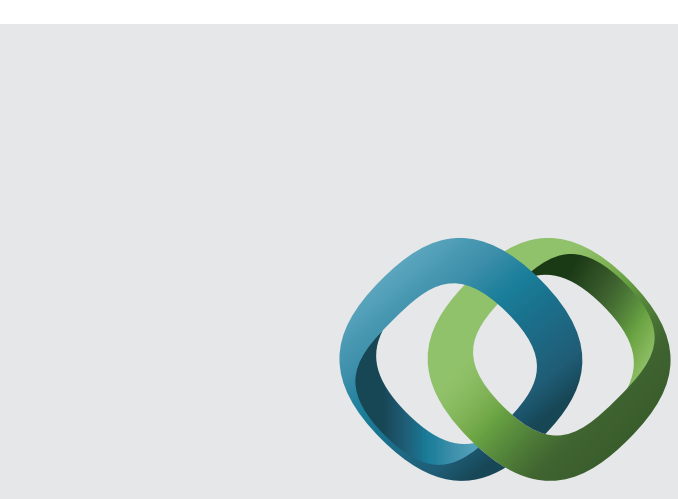

\section{Hindawi}

Submit your manuscripts at

http://www.hindawi.com
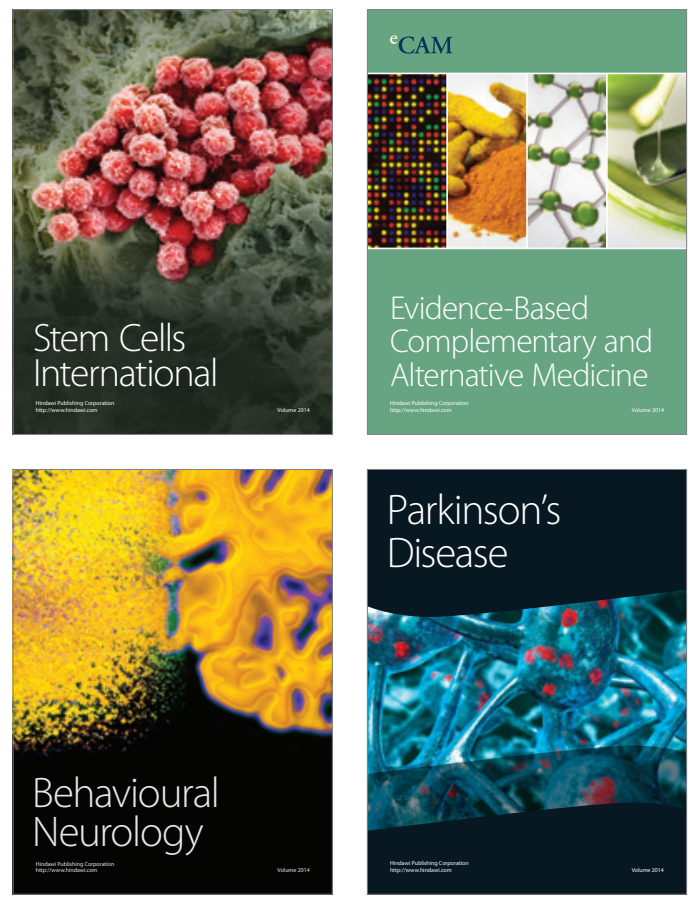
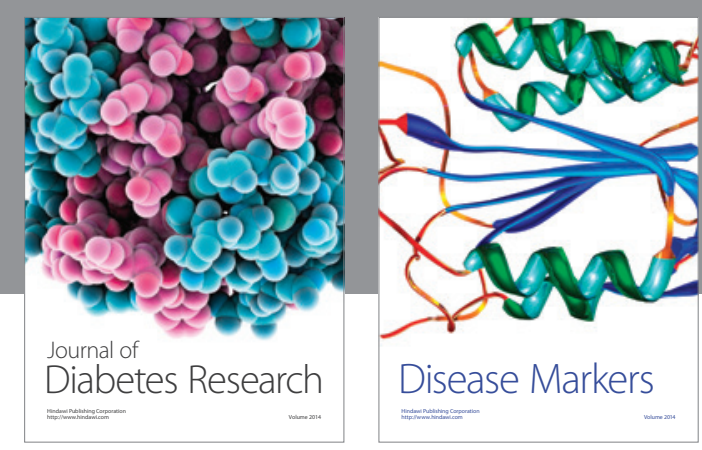

Disease Markers
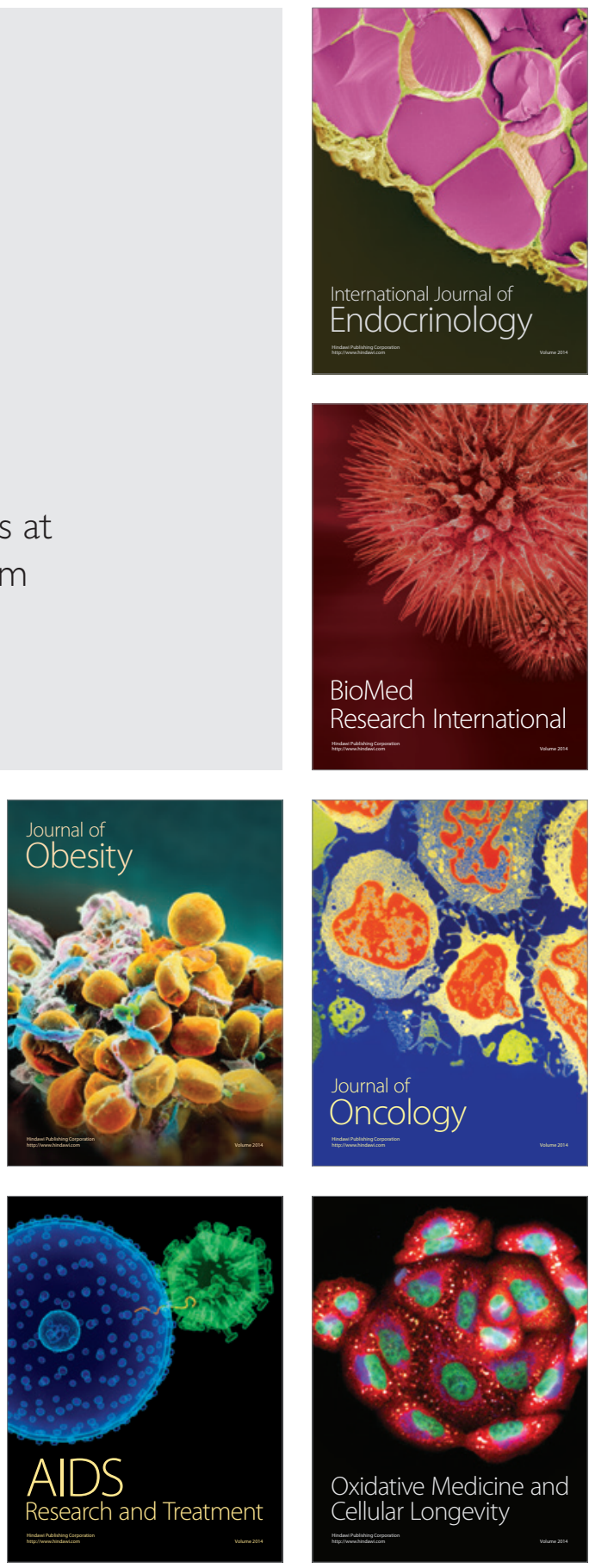